\title{
A TRILHA AMBIENTAL INTERPRETATIVA EM UMA UNIDADE DE CONSERVAÇÃO COMO FERRAMENTA DE SENSIBILIZAÇÃO DE ESCOLARES: UMA ABORDAGEM QUANTITATIVA NA REDE MUNICIPAL DE ENSINO DE JOINVILLE, SANTA CATARINA
}

\author{
Douglas Macali Souza ${ }^{1}$
}

Marta Jussara Cremer ${ }^{2}$

\section{Resumo:}

A Educação Ambiental é um processo que busca elucidar valores e desenvolver atitudes que permitam adotar uma posição consciente e participativa. Contudo, cada indivíduo percebe, reage e responde diferentemente às ações sobre o ambiente em que vive, resultado de sua percepção individual. Nesse sentido, práticas de contato com a natureza são uma excelente estratégia de educação ambiental, pois permitem adquirir conhecimentos através de uma experiência direta com o meio ambiente. Sabendo disso, a pesquisa buscou dimensionar a influência da realização de uma trilha interpretativa sobre a percepção ambiental de escolares. Para quantificar as mudanças apresentadas, fez-se uso de escalas visuais analógicas em dois momentos, antes e depois da atividade na trilha interpretativa em uma unidade de conservação. Os resultados permitiram concluir que, após o contato direto com a natureza, os alunos manifestaram mudanças significativas acerca de seus conhecimentos e sentimentos em relação ao meio ambiente.

Palavras-chave: Percepção Ambiental. Trilhas Interpretativas. Escala Visual Analógica.

\section{THE ENVIRONMENTAL INTERPRETATIVE TRAIL IN A UNIT CONSERVATION AS A TOOL FOR RAISING AWARENESS OF STUDENTS: A QUANTITATIVE APPROACH IN MUNICIPAL SCHOOL SYSTEM IN JOINVILLE, SANTA CATARINA}

\begin{abstract}
:
Environmental Education is a process that seeks to elucidate values and develop attitudes that allow adopt a aware and participatory position. However, each individual perceives, reacts and responds differently to the actions on the environment in which he lives as a result of their individual perception. In this sense, practices of contact with the nature are an excellent strategy for environmental education, since they allow to acquire knowledge through direct experience with the environment. Knowing this, the objective in this research was determining the influence of an interpretative trail on the environmental perception of the students. To quantify the changes submitted, we used analogical visual scales in two moments, before and after the activity in the interpretative trail in a unit conservation. The results allowed us to conclude that, after the direct contact with nature, the students showed significant changes about their knowledge and feelings in relation to the environment.
\end{abstract}

Keywords: Environmental Perception. Interpretive Trails. Visual Analogue Scale.

\footnotetext{
${ }^{1}$ Programa de Pós-Graduação nível Mestrado em Saúde e Meio Ambiente, Universidade da Região de Joinville - UNIVILLE.douglas@institutocomar.org.br

${ }^{2}$ Docente e Pesquisadora na Universidade da Região de Joinville - UNIVILLE, Centro de Ciências Humanas e Biológicas, Departamento de Ciências Biológicas, São Francisco do Sul, SC. mjc2209@ yahoo.com.br
} 


\title{
EL SENDERO INTERPRETATIVO DEL MEDIO AMBIENTE EN UN ÁREA PROTEGIDA COMO HERRAMIENTA DE SENSIBILIZACIÓN DE LOS ESTUDIANTES: UN ENFOQUE CUANTITATIVO EN EL SISTEMA DE EDUCACIÓN MUNICIPAL DE JOINVILLE, SANTA CATARINA
}

\begin{abstract}
Resumen:
La educación ambiental es un proceso que busca elucidar los valores y desarrollar actitudes que permiten adoptar una posición consciente y participativa. Sin embargo, cada individuo percibe, reacciona y responde de manera diferente a las acciones sobre el medio ambiente en el que vive, resultado de su percepción individual. En este sentido, las prácticas de contacto con la naturaleza son una excelente estrategia de educación ambiental, ya que permiten adquirir conocimientos a través de una experiencia directa con el medio ambiente. Sabiendo esto, la investigación trató de dimensionar la influencia de la realización de un sendero interpretativo en la conciencia ambiental de los estudiantes. Para cuantificar los cambios presentados, se hizo uso de escalas analógicas visuales en dos etapas, antes y después de la actividad del sendero interpretativo en una unidad de conservación. Los resultados mostraron que después del contacto directo con la naturaleza, los estudiantes mostraron cambios significativos sobre sus conocimientos y sentimientos sobre el medio ambiente.
\end{abstract}

Palabras-clave: Percepción Ambiental. Senderos Interpretativos. Escala Analógica Visual.

\section{Introdução}

A conservação da biodiversidade e suas diversas abordagens é um tema bastante debatido na atualidade. Em todo o mundo, comunidades biológicas que levaram milhões de anos para evoluir ao estado atual vêm sendo devastadas por ações antrópicas (SILVA; CANDIDO; FREIRE, 2009). As ameaças à diversidade biológica são duplamente aceleradas, seja pelo rápido aumento na população humana ou pelo acelerado consumo de matérias primas (PRIMACK; RODRIGUES, 2001; CULLEN; RUDRAN. VALLADARES-PÁDUA, 2004). Nas grandes cidades brasileiras, a vegetação original está cedendo lugar, a cada dia, para a área urbana, comportando construções, ruas e avenidas, entre outros. Essa ocupação urbana gera diversos problemas, como: cidades mais quentes e secas, problemas com enchentes, erosões, poluição atmosférica, do solo, da água e, ainda, com a diminuição das áreas naturais e da fauna local. Esses problemas acabam culminando em uma cidade menos atrativa (PINHEIRO, 2004).

A criação de Unidades de Conservação (UCs) vem se constituindo numa das principais formas de intervenção governamental para reduzir as perdas da biodiversidade, face à degradação ambiental decorrente do avanço da sociedade sobre áreas naturais (VALLEJO, 2002). Além da proteção da biodiversidade, as UCs prestam importantes serviços ambientais, como a regulação climática, o fornecimento de água e ar puro, entre outros. Logo, esses remanescentes tornam-se importantes para a manutenção do microclima, abrigo da fauna, além de manter a qualidade ambiental e proporcionarem proveitos de caráter social, estético, educativo e psicológico para as populações (DRAY; SIMONETTI, 2012).

Devido a seus atributos naturais, as áreas protegidas são muito procuradas para o turismo e, ainda, como ferramenta de ensino para os professores, pois por meio de trilhas que interpretam a natureza é possível que o aluno tenha a oportunidade para a reflexão sobre os seus valores (TABANEZ; PÁDUA; SOUZA, 1996). Ao refletir sobre esta questão, passam a reconhecer valores únicos dos locais onde vivem, aumentando sua autoestima e gerando um sentimento de orgulho em manter essa riqueza (ALVARENGA, 2005). 
De acordo com Vasconcellos e Ota (2000), as trilhas podem ser definidas como caminhos através do espaço geográfico, histórico e cultural, podendo ser consideradas interpretativas quando há recursos que são traduzidos para os visitantes, com base em temas predeterminados através de guias, folders ou placas e painéis. Ainda de acordo com os autores, em termos práticos, as trilhas interpretativas têm o objetivo de incentivar o visitante a um novo campo de percepções, levando-os a observar, questionar, experimentar, sentir e descobrir os vários sentidos e significados associados aos temas relacionados. Menghini (2005) relata que a realização de trilhas interpretativas procura propiciar uma compreensão crítica do meio natural, despertando valores e atitudes que permitem uma participação responsável na busca de soluções para reverter ou prevenir os problemas socioambientais, bem como atuar na melhoria e proteção do meio ambiente.

Estudos sobre percepção ambiental vêm sendo utilizados como instrumento de gestão em áreas do conhecimento ligadas aos temas educacional, social e ambiental (MARIN; TORRES; COMAR, 2003), buscando gerar resultados que possam servir como referência e para melhorar a qualidade de vida das pessoas e da natureza. Nessa mesma linha, Freitas e Ribeiro (2007) afirmam que os estudos que envolvem a percepção ambiental têm recebido destaque por associar várias áreas, dentre elas a psicologia, a sociologia e a ecologia, ajudando na compreensão das expectativas da população em relação ao local onde vive, bem como no reconhecimento dos fatores que afetam a qualidade de vida ou o bem-estar social.

A capacidade de perceber, conhecer, representar, pensar e se comunicar permite ao homem moldar os lugares e as paisagens. Suas respostas ambientais são, então, influenciadas pelas interpretações que ele é capaz de fazer a partir de suas experiências perceptivas presentes e passadas, de suas expectativas, propósitos, aspirações, gostos e preferências. Assim sendo, percepção no entendimento de Tuan (1980, p. 4) "é tanto a resposta dos sentidos aos estímulos externos, como a atividade proposital, na qual certos fenômenos são claramente registrados, enquanto outros retrocedem para a sombra ou são bloqueados". O autor afirma, ainda, que a abordagem da percepção ambiental parte do pressuposto que perceber é adquirir conhecimentos pelos órgãos dos sentidos, ou seja, compreender.

Para Carvalho (2006), o processo de percepção antecede a atribuição de significado que, obviamente, refere-se a algo maior do que simplesmente o sujeito e o objeto, é algo macro (a soma do todo é maior que a soma das partes) e, nesse sentido, estão embutidos seus valores culturais, sociais e econômicos.

Para Fiori (2002), os estudos que envolvem a percepção do ambiente são realizados levando em consideração a interação do ser humano com a paisagem, onde o elemento humano compreende a experiência passada, o conhecimento, expectativas e contexto sociocultural dos indivíduos e dos grupos. Nessa direção, Tuan (1980, p. 5) apresenta seu conceito de "topofilia", "o elo afetivo entre a pessoa e o lugar ou ambiente físico". Para o autor, percepção, atitudes, valores e suas consequências - a visão de mundo - devem ser o foco no entendimento da relação homem x natureza e seus respectivos reflexos.

Nessa mesma linha, Rauber e Neto (2012) consideram que estudos sobre percepção ambiental têm sido um meio de compreender como os sujeitos de diversas realidades compreendem suas ações e se sensibilizam em relação ao meio ambiente. E isso envolve uma série de fatores sensoriais e subjetivos, incluindo valores sociais, culturais e atitudes ambientais das comunidades em determinada realidade.

Segundo essa contextualização, a educação ambiental (EA) deve assumir um papel transformador, uma vez que seu grande desafio é o de mudar valores e comportamentos (FERRANDEZ; SARRAMONA, 1975). Um trabalho de EA deve reconhecer que a escola não é o único espaço onde acontece o aprendizado, isto é, não é obrigatoriamente nele que se inicia e se esgota a aula (ALVARENGA, 2005). Guimarães (2000, p. 23) entende que a EA seja uma "metodologia de ação, de forma a tirar o aluno da posição de mero espectador da 
realidade que o cerca para colocá-lo como real participante dessa realidade", permitindo ao aluno desenvolver o "pensamento reflexivo e crítico".

Sabendo disso, o presente estudo teve como objetivo dimensionar a influência do contato direto com a natureza, através da realização de uma trilha interpretativa na Unidade de Conservação Parque Municipal Morro do Finder, sobre a percepção ambiental de escolares da rede municipal de ensino de Joinville.

\section{Local de Estudo}

Localizado na região sul do Brasil, no nordeste do estado de Santa Catarina (Figura 1), o município de Joinville (26 $16^{\circ} \mathrm{S}$ e $\left.48^{\circ} 50^{\prime} \mathrm{W}\right)$ abrange uma área de $1.134,03 \mathrm{~km}^{2}$, da qual aproximadamente $480 \mathrm{~km}^{2}$ são áreas preservadas, localizadas nas encostas da Serra do Mar, morros isolados e manguezal (ROCHA, 2006).

Figura 1 - Localização do Município de Joinville/SC.



Fonte: ArcMap - Sirgas Datum 2000. Diogo A. Moreira (2014)

O município ocupa uma faixa estreita de terra que se estende desde o litoral, passando pela planície litorânea e as escarpas da Serra do Mar, até o Planalto Ocidental, com área territorial em zona urbana $(29,35 \%)$ e zona rural (70,65\%) (FUNDEMA, 2011). A leste encontramos a Baía da Babitonga, importante formação de águas marinhas interiores, com margens colonizadas por vegetação nativa típica de manguezais, correspondendo a $75 \%$ do total deste ecossistema no Estado, com área aproximada de 6.200ha (IBAMA, 1998). Este é um importante ecossistema costeiro, que atua, também, como barreira física para a expansão da cidade. Dentre os ecossistemas vegetais que ocorrem na região, destacam-se a Floresta Ombrófila Densa, com cerca de $680 \mathrm{Km}^{2}$, e os manguezais, com $36 \mathrm{~km}^{2}$. A importância desses ecossistemas revela-se pela área de cobertura do território (IPPUJ, 2014).

Localizado na área central de Joinville, o Parque Municipal Morro do Finder (PMMF - Figura 2) é um local turisticamente importante e muito visitado, cujo atrativo é a sua floresta extremamente significativa. Exerce papel fundamental no ambiente urbano, através da estabilização climática, redução de ruído, abrigo para espécies animais e, também, como áreas de lazer para a população. O PMFF é uma Unidade de Conservação de Proteção Integral, criada pelo Decreto Municipal $n^{\circ} 7.056 / 93$ para proteger um importante remanescente de Floresta Ombrófila Densa inserido na paisagem urbana da cidade, com 501.730,24 m². 
Figura 2 - Localização do Parque Municipal Morro do Finder, em Joinville/SC.

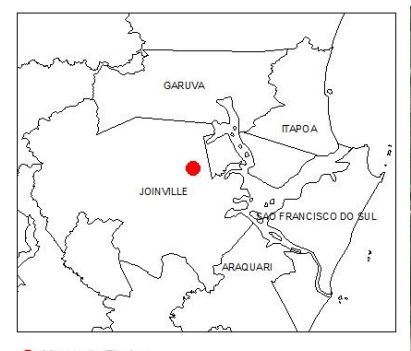

Morro do Finder

Prefeitura Municipal de Joinville. 2010. Escala 1:10.000/1:5.000. SimGeo 2010.


Fonte: ArcMap - Sirgas Datum 2000. Diogo A. Moreira (2014)

\section{Metodologia}

A pesquisa foi conduzida com alunos do Ensino Fundamental II (do $7^{\circ}$ ao $9^{\circ}$ ano) de uma escola da rede municipal de ensino de Joinville, localizada no bairro Jardim Paraíso. No total, 196 alunos participaram da pesquisa, sendo que o questionário de 161 foram analisados. Os alunos tinham idades entre 13 e 16 anos.

O método escolhido para analisar a percepção ambiental dos alunos foi a escala visual analógica (NORRIS, 1971), avaliada por meio da aplicação de questionários com 10 perguntas. A resposta de cada pergunta foi marcada em uma escala específica formada por uma linha de $100 \mathrm{~mm}$, sendo que em cada extremidade estavam dispostos os números 0 e 10 , para as questões de conhecimento. Para as questões de sentimentos, nas extremidades estavam dispostos os sentimentos relativos à temática, por exemplo feliz/triste. As escalas tiveram o objetivo de mensurar se os pesquisados apresentaram (ou não) mudanças nos sentimentos e conhecimentos sobre o meio ambiente após a realização da trilha interpretativa. $\mathrm{O}$ questionário abordou temáticas como a Mata Atlântica, arborização, desmatamento, poluição e o contato com a natureza.

Os questionários considerados como pré-teste foram aplicados pelos pesquisadores aos alunos, na própria sala de aula, separadamente para cada turma, aproximadamente uma hora antes da atividade de campo na trilha. O questionário foi aplicado sem que houvessem intervenções quanto ao tema ambiental, a fim de obter um diagnóstico prévio de percepção ambiental dos pesquisados sobre o meio ambiente. Com o objetivo de uniformizar o grupo e evitar vieses que poderiam ser ocasionados por sujeitos experimentais que já tivessem alguma 
experiência anterior em relação ao local escolhido para a realização da pesquisa (PMMF), o questionário apresentou uma questão destinada a determinar se o aluno já havia visitado o parque anteriormente. Em caso afirmativo, os questionários desses alunos foram descartados das análises.

Após a aplicação do pré-teste, no mesmo dia os alunos foram levados a conhecer in loco o PMMF por meio de uma atividade guiada com um biólogo através de uma trilha interpretativa, com a presença dos pesquisadores. Ao chegar ao PMMF, o guia fez uma breve apresentação da unidade de conservação, falando dos objetivos de sua criação, principais espécies de fauna e flora encontradas e importância do parque para a região. Foi percorrida a Trilha dos Palmiteiros, com aproximadamente 500 metros de comprimento e duração aproximada de percurso de 40 minutos, entre caminhada e atividades. Na trilha encontram-se diversas placas informativas, com informações sobre a fauna e flora encontrada no PMMF.

As atividades na trilha foram baseadas nas temáticas que compuseram o questionário previamente respondido pelos alunos. Sabendo que percebemos e construímos nossas percepções pelos sentidos (visão, tato, olfato, audição e paladar), o guia desenvolveu atividades interpretativas explorando as formas, cores, odores e sons da trilha visitada. Essas atividades foram desenvolvidas em pontos estratégicos, previamente mapeados pelos pesquisadores e pelo guia. Conforme proposto por Magro e Freixêdas (1998), para a seleção dos pontos, foi necessário observar o local e realizar levantamento de seus recursos naturais. Assim, após essa observação, foi possível selecionar os pontos com maior atratividade da trilha para se desenvolver as atividades.

Durante todo o percurso da trilha, buscou-se despertar o espírito investigativo e a reflexão crítica dos alunos ao tentar construir, em conjunto, o conhecimento. Procurou-se intercalar a explicação dos aspectos contidos nos pontos interpretativos com alguns questionamentos, fazendo com que os alunos participassem da construção dos conteúdos e temáticas abordadas durante a trilha.

A primeira atividade foi desenvolvida logo na entrada da trilha, onde foi possível sentir a mudança (queda) de temperatura e observar a diferença na vegetação (tamanho das árvores). Visando a reflexão dos alunos, o guia questionou se eles haviam sentido a diferença de temperatura do momento no qual estavam na escola, em relação ao local onde agora estavam, na entrada da trilha. Muitos alunos relataram sentir essa mudança na temperatura. Naquele momento, a temática microclima e Mata Atlântica foi abordada pelo guia, onde foi relatada a importância das árvores para a regulação do clima. Ao falar das árvores, o guia aproveitou a temática para tratar da problemática que é a destruição da Mata Atlântica, mostrando sua importância para a sobrevivência das espécies que nela habitam.

A segunda atividade, alguns metros à frente, foi realizada logo abaixo de uma palmeira, rodeada por suas sementes. Os alunos foram convidados a pegar e tocar as sementes, para sentir sua textura, momento no qual foi feita a relação entre a palmeira e os tucanos encontrados no parque. Foi relatado aos alunos que a semente é recoberta por uma camada de polpa fibrosa que atrai os pássaros, onde, devorada a fruta, somente a polpa é digerida pelos tucanos. A semente é expelida junto com as fezes, germina no solo, e produz uma nova palmeira. Isso permite que a palmeira se espalhe pelo Parque. Como a fruta que cai da palmeira que a produziu dificilmente germina, a palmeira depende dos tucanos para se espalhar. Na ocasião, foram trabalhados os temas fauna, flora e a extinção de espécies, bem como seu impacto para o meio ambiente.

$\mathrm{Na}$ terceira atividade foi explorado o tema lixo e poluição. No decorrer da trilha (infelizmente) foi possível visualizar diversos materiais (papéis de bala, embalagens, latas) que são comumente utilizados pelos visitantes do parque e descartados incorretamente. Ao fazer a parada, o guia questionou os alunos se eles haviam percebido, durante a caminhada até aquele local, algo de errado na trilha. Grande parte dos alunos sinalizou ter percebido a 
quantidade de lixo encontrada em alguns pontos do trajeto. Na ocasião, foram trabalhadas as temáticas de consumo consciente, poluição e seu impacto ao meio ambiente. $\mathrm{O}$ guia procurou dar exemplos para os alunos refletirem como o impacto do lixo pode afetar no seu dia a dia, seja em casa, na escola ou no bairro onde moram.

Aproximadamente 30 dias após a visita ao parque, os pesquisadores retornaram à escola, onde os questionários foram reaplicados (pós-teste) a todos os participantes da pesquisa. O pós-teste teve como objetivo analisar a eficácia da estratégia de contato direto com a natureza sobre a percepção ambiental dos alunos. Dessa forma, foi possível comparar os resultados do pré-teste com o pós-teste, analisando se houve mudança na forma como os alunos percebem o meio ambiente, bem como se houve mudança de conhecimento quanto as problemáticas apresentadas.

\section{Análises de Dados}

Foi mensurado o valor marcado na escala associada a cada questão com uma régua. Os dados foram analisados quanto a sua normalidade, utilizando os testes de Shapiro-Wilk e de Kolmogorov-Smirnov com correção de Lilliefors. O resultado indicou que os dados não seguiram uma distribuição normal e, por esse motivo, foram utilizados testes não paramétricos em todas as análises estatísticas realizadas. Por serem amostras pareadas, pois foram considerados os mesmos alunos no pré-teste e no pós-teste, foi escolhido o teste de Wilcoxon pareado, que analisa diferenças entre médias dependentes (pré-teste e pós-teste). Conforme Siegel (1975), o teste de Wilcoxon pareado é aplicado a dados pareados, como, por exemplo, para comparar duas amostras que são realizadas nos mesmos indivíduos, do tipo antes e depois, funcionando como um substituto do teste-T do campo paramétrico. O nível de rejeição da hipótese de nulidade foi de 0,05 (probabilidade alfa de 5\%).

\section{Resultados e Discussão}

Foi possível observar que a saída de campo despertou muito interesse e euforia nos alunos, pela expectativa de conhecerem um local nunca antes visitado. É válido lembrar que a comunidade onde a escola está inserida é de baixa renda e com grande vulnerabilidade social, sendo que muitos alunos ainda não haviam tido a oportunidade de sair de seu bairro, enquanto outros nunca haviam ido tão distante da escola. Nos relatos verbais durante o trajeto de ida (escola ao parque), essa euforia de estar passeando foi ressaltada por vários alunos, bem como no percurso de volta para a escola, onde muitos alunos relataram sua vontade de permanecer por mais tempo no PMMF.

Para os pesquisadores, esse já é um indício da importância de utilizar atividades educativas diferenciadas, que levem a sociedade a conhecer a natureza de perto, seja próximo ou longe da comunidade. Ao refletir sobre os valores do meio ambiente, as pessoas passam a reconhecer valores únicos nos locais onde vivem, aumentando sua autoestima e gerando um sentimento de orgulho em manter essa riqueza (ALVARENGA, 2005).

A Tabela 1 apresenta os valores médios das respostas, comparando as médias dos prétestes e pós-testes, com a variação em percentual entre ambos. Nessa escala, o valor próximo de 0 representa um menor conhecimento/sentimento por parte do pesquisado e o valor próximo de 10 representa maior conhecimento/sentimento sobre o tema em questão. 
Tabela 1 - Valor médio, desvio padrão e variação das respostas entre os testes para as questões de escalas de sentimentos e conhecimentos dos alunos que visitaram o Parque Municipal Morro do Finder, Joinville/SC ( $\mathrm{n}=161)$

\begin{tabular}{|c|c|c|c|c|c|}
\hline \multirow{2}{*}{$\begin{array}{l}\text { Perguntas } \\
\text { P1. Você acha que a Mata Atlântica é } \\
\text { importante? }\end{array}$} & \multicolumn{2}{|c|}{$\begin{array}{l}\text { Pré-Teste } \\
\text { Média }\end{array}$} & \multicolumn{2}{|c|}{$\begin{array}{l}\text { Pós-Teste } \\
\text { Média }\end{array}$} & \multirow{2}{*}{$\begin{array}{l}\text { Variação } \\
(\%)\end{array}$} \\
\hline & 7,31 & $\pm 1,68$ & 8,54 & $\pm 1,25$ & \\
\hline $\begin{array}{l}\text { P2. Você gostaria que seu bairro fosse mais } \\
\text { arborizado? }\end{array}$ & 6,95 & $\pm 1,82$ & 8,61 & $\pm 1,37$ & 23,91 \\
\hline $\begin{array}{l}\text { P3. Você acha que jogar lixo nos rios pode } \\
\text { afetar sua vida? }\end{array}$ & 7,35 & $\pm 1,24$ & 7,47 & $\pm 1,60$ & 1,64 \\
\hline $\begin{array}{l}\text { P4. Você acha que o desmatamento pode afetar } \\
\text { sua vida? }\end{array}$ & 7,40 & $\pm 1,65$ & 8,23 & $\pm 1,56$ & 11,20 \\
\hline $\begin{array}{l}\text { P5. Você acha que a extinção de plantas e } \\
\text { animais pode afetar sua vida? }\end{array}$ & 7,27 & $\pm 1,61$ & 7,41 & $\pm 1,54$ & 1,96 \\
\hline P6. A preservação da Mata Atlântica é: & 7,09 & 4 & 0 & 9 & 12,83 \\
\hline $\begin{array}{l}\text { P7. O que você sente quando ouve falar sobre a } \\
\text { extinção de plantas e animais? }\end{array}$ & 6,64 & $\pm 1,70$ & 7,70 & 83 & 16,00 \\
\hline $\begin{array}{l}\text { P8. Quando estou em contato direto com a } \\
\text { Natureza eu me sinto: }\end{array}$ & 6,45 & $\pm 1,97$ & 7,53 & $\pm 1,85$ & 16,78 \\
\hline $\begin{array}{l}\text { P9. O que você sente quando vê árvores sendo } \\
\text { cortadas? }\end{array}$ & 7,16 & $\pm 1,57$ & 7,45 & $\pm 1,67$ & 3,96 \\
\hline $\begin{array}{l}\text { P10. Como você fica quando vê lixo jogado no } \\
\text { chão? }\end{array}$ & 7,41 & $\pm 1,81$ & 7,96 & $\pm 1,77$ & 7,42 \\
\hline
\end{tabular}

Todas as respostas do pós-teste apresentaram um aumento no valor em relação ao préteste. Isto indica que os alunos, após participarem da atividade de contato direto com a natureza, manifestaram uma mudança positiva nos conhecimentos e sentimentos para os temas relacionados nas perguntas. A diferença entre o pré-teste e o pós-teste foi significativa para todas as questões, destacadas em negrito, com exceção da questão número 3 (Você acha que jogar lixo nos rios pode afetar sua vida?) (Tabela 2).

Tabela 2 - Resultados do Teste de Wilcoxon pareado para as amostras pareadas dos alunos que visitaram o Parque Municipal Morro do Finder, Joinville/SC.

\begin{tabular}{llll}
\hline Perguntas & $\mathbf{n}$ & Valor $\boldsymbol{z}$ & $\begin{array}{l}\text { Valor } \\
\boldsymbol{p}\end{array}$ \\
\hline P1. Você acha que a Mata Atlântica é importante? & 145 & $\mathbf{8 , 6 9 5}$ & $\mathbf{0 , 0 0 0}$ \\
P2. Você gostaria que seu bairro fosse mais arborizado? & 143 & $\mathbf{9 , 9 0 2}$ & $\mathbf{0 , 0 0 0}$ \\
P3. Você acha que jogar lixo nos rios pode afetar sua vida? & 150 & 1,539 & 0,124 \\
P4. Você acha que o desmatamento pode afetar sua vida? & 139 & $\mathbf{6 , 7 2 2}$ & $\mathbf{0 , 0 0 0}$ \\
P5. Você acha que a extinção de plantas e animais pode afetar & 139 & $\mathbf{2 , 3 7 6}$ & $\mathbf{0 , 0 1 8}$ \\
sua vida? & 132 & $\mathbf{7 , 5 7 2}$ & $\mathbf{0 , 0 0 0}$ \\
P6. A preservação da Mata Atlântica é: & &
\end{tabular}


P7. O que você sente quando ouve falar sobre a extinção de plantas e animais?

P8. Quando estou em contato direto com a Natureza eu me sinto:

P9. O que você sente quando vê árvores sendo cortadas?

P10. Como você fica quando vê lixo jogado no chão?
$121 \quad \mathbf{7 , 9 4 0} \quad \mathbf{0 , 0 0 0}$

$130 \quad \mathbf{8 , 0 8 4} \mathbf{0 , 0 0 0}$

$127 \quad \mathbf{3 , 5 0 2} \mathbf{0 , 0 0 0}$

$\begin{array}{lll}140 & \mathbf{5 , 5 6 8} & \mathbf{0 , 0 0 0}\end{array}$

Os dados indicam que a estratégia de contato direto com a natureza foi significativa para o grupo estudado, com um aumento no valor das respostas manifestadas pelo aluno. $\mathrm{Ou}$ seja, isto indica que a percepção dos alunos em relação à natureza modificou-se, com sentimentos mais positivos e maior conhecimento apresentado em relação às temáticas abordadas. Resultado que corrobora aquele encontrado por Alvarenga e Nogueira-Filho (2005), que quantificaram as mudanças de sentimentos e valores com o uso de estratégia similar (contato direto com a natureza analisado pelo uso de escala visual analógica). Os pesquisadores utilizaram quatro tratamentos diferenciados (1 - atividades somente sala de aula, 2 - visita à trilha, 3 - atividades em sala de aula com visita à trilha e 4 - visita a um centro de recuperação do bicho-preguiça) e também concluíram que as estratégias que propiciam aos alunos um contato direto com a natureza são as que melhores resultados apresentam, pois proporcionam um aumento de conhecimento e mudanças de valores e sentimentos. Neiman (2007), aplicou um método semelhante a alunos de graduação e constatou que o contato com a natureza gerou mudanças significativas, com uma transformação dos conhecimentos, valores e atitudes em prol do ambiente.

\subsection{Questões de conhecimento}

A Figura 3 apresenta os resultados para as perguntas de conhecimento. A questão $P 1$ Você acha que a Mata Atlântica é importante? foi a que apresentou a segunda maior variação $(16,89 \%)$ no valor das respostas, passando de um valor médio de 7,31 para 8,54. A análise estatística indicou que essa diferença foi significativa $(p=0,000)$.

Esse aumento nos valores ligados ao conhecimento pode estar relacionado às características do local visitado pelos alunos, haja visto que o PMMF é uma UC inteiramente inserida na Mata Atlântica. A temática foi abordada de diversas formas durante as atividades em trilha, inclusive com informações sobre o grau de devastação da mesma em nosso Estado, assim como de algumas espécies da fauna, por meio de uma placa informativa. Alvarenga e Nogueira-Filho (2005) consideram que visitar uma UC constitui uma ótima opção para que os alunos assimilem conhecimentos e modifiquem sua percepção sobre a Mata Atlântica. 
Figura 3 - Valor médio e intervalo de confiança do pré-teste e pós-teste para as questões: P1Você acha que a Mata Atlântica é importante?; P2 - Você gostaria que seu bairro fosse mais arborizado?; P3 - Você acha que jogar lixo nos rios pode afetar sua vida?; P4 - Você acha que o desmatamento pode afetar sua vida?; P5 - Você acha que a extinção de plantas e animais pode afetar sua vida?; e P6 - A preservação da Mata Atlântica é. (Pré-teste n=161; Pós-teste $\mathrm{n}=161$ )

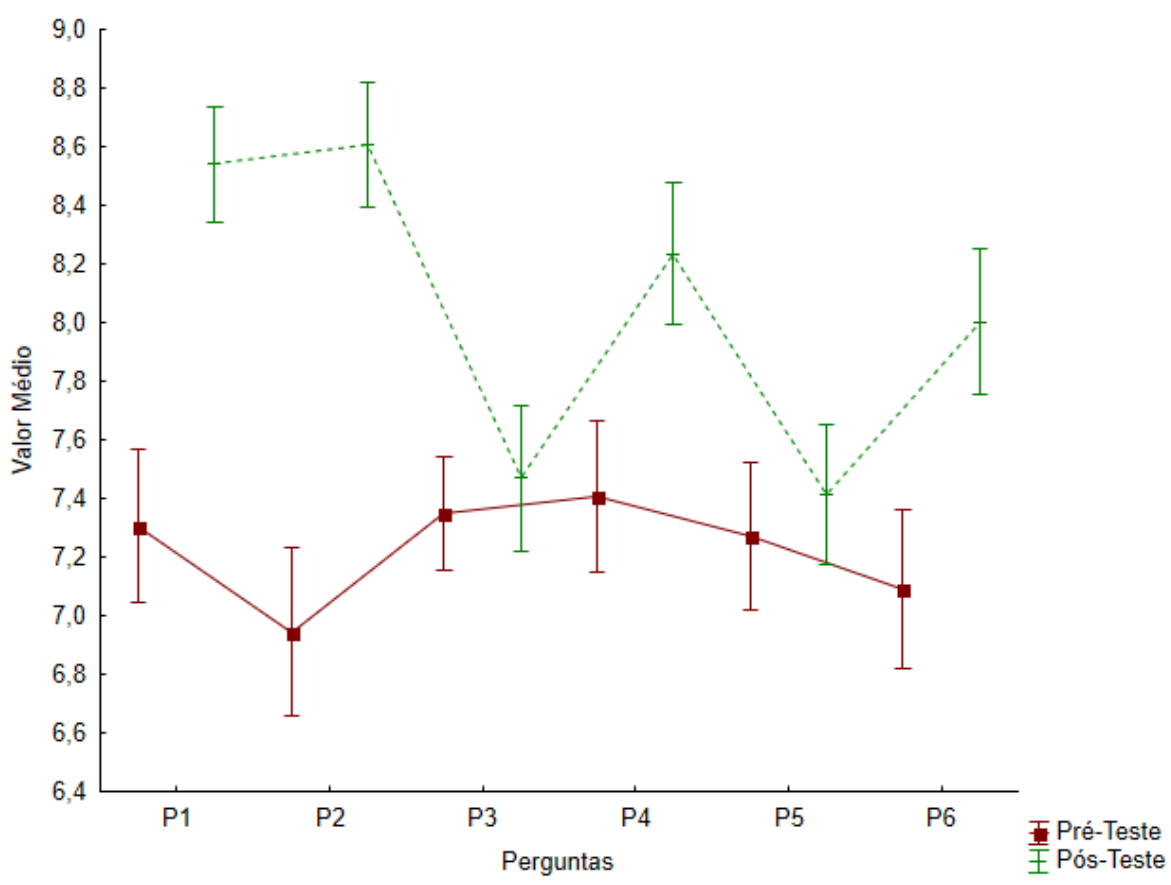

Fonte: Douglas Macali Souza (2015)

A questão P2 - Você gostaria que seu bairro fosse mais arborizado? foi a que apresentou a maior variação entre as perguntas do questionário $(23,91 \%)$, passando de um valor médio de 7,31 para 8,54. As análises estatísticas indicaram que essas mudanças foram significativas $(p=0,000)$. Os resultados indicam que a percepção dos alunos em relação à arborização modificou-se após a visita à UC, o que pode estar relacionado à realidade do local onde vivem, pois o entorno da escola e do bairro são locais com poucas árvores. A escassez de árvores no bairro onde a escola está inserida está relacionada, principalmente, ao histórico de ocupação do local, caracterizado pelas invasões.

Conhecer um local arborizado como o PMMF, que tem muitas árvores, um ar mais limpo e mais aves, pode ter mudado a forma de os alunos perceberem o seu entorno, levandoos a compreender e valorizar os benefícios que a arborização pode trazer para a sua realidade, ou seja, o bairro onde vivem. Segundo Seniciato e Cavassan (2004), em uma aula tradicional a importância das árvores para a qualidade do ar seria explorada de forma teórica, com informações sobre as características físicas do ambiente, como as variações de temperatura e umidade atmosférica, os percentuais de composição do ar e de desprendimento dos gases nos processos de fotossíntese e respiração. Por outro lado, os sentimentos despertados pela 
vivência num ambiente bem arborizado não poderiam ser efetivamente sentidos se não fosse pelo contato direto, da forma como foi realizado neste estudo.

A questão P3 - Você acha que jogar lixo nos rios pode afetar sua vida? foi a única que não apresentou uma alteração significativa $(p=0,124)$. Isso significa que os alunos não mudaram sua percepção em relação ao tema.

Durante uma das atividades na trilha, que aconteceu próxima a uma nascente de rio, o guia questionou os alunos sobre a falta de água que o Estado de São Paulo vinha passando. O guia convidou os alunos a refletirem sobre a falta de água, relacionando a importância do rio Cubatão com o dia a dia deles. É importante salientar que o rio Cubatão é responsável por $65 \%$ do abastecimento de água do município. É possível que, por uma falha na abordagem durante as atividades, os alunos não tenham conseguido relacionar a importância dessa temática

Para a questão P4 - Você acha que o desmatamento pode afetar sua vida?, os valores médios das respostas passaram de 7,40 para 8,23. As análises estatísticas indicam que essas mudanças foram significativas $(\mathrm{p}=0,000)$. Os resultados indicam que houve uma mudança na manifestação de conhecimento quanto à temática do desmatamento.

Esse aumento apresentado no valor das respostas, com uma variação de 11,20\% entre os pré-testes e pós-testes, é similar ao encontrado por Alvarenga e Nogueira-Filho (2005), que observaram diferenças (positivas) entre os pré-testes e pós-testes, quando questionaram se o desmatamento na borda da UC poderia ser prejudicial. Conforme os autores, após a prática de contato com a natureza, os alunos passaram a manifestar que o desmatamento na borda da UC era prejudicial para o local visitado.

Na questão P5 - Você acha que a extinção de plantas e animais pode afetar sua vida? o valor médio das respostas passou de 7,27 no pré-teste para 7,41 no pós-teste. As análises estatísticas indicaram que a alteração foi significativa $(\mathrm{p}=0,018)$, sugerindo que houve uma mudança na percepção ambiental dos alunos em relação à temática. Essa questão está diretamente ligada à segunda atividade que ocorreu nas trilhas, realizada embaixo de uma palmeira rodeada por suas sementes. Na ocasião, foram abordados os temas fauna, flora e a extinção de espécies, bem como seu impacto para o meio ambiente. Alvarenga e NogueiraFilho (2005) também observaram mudanças significativas na percepção dos alunos ao trabalharem a temática extinção de plantas e animais associada à realização de atividades de contato com a natureza. Silveira et al. (2011) relatam que 92,68\% dos acadêmicos entrevistados apresentaram um aumento no conhecimento do conceito de extinção após a realização de atividades nas UCs Parque Estadual do Cantão e Parque Estadual do Jalapão. De acordo com os autores, as trilhas interpretativas se apresentaram como notáveis recursos didáticos, capazes de incentivar a capacidade de observação e reflexão, viabilizando, assim, a sensibilização e a conscientização ambiental dos graduandos.

Na questão P6 - A preservação da Mata Atlântica é, a média das respostas no pré-teste foi de 7,09, enquanto no pós-teste foi de 8,00, o que representou um aumento de 12,83\%, representativa de uma variação significativa $(\mathrm{p}=0,000)$. Os dados indicam que os alunos mudaram sua percepção em relação a importância da preservação da Mata Atlântica e de sua urgência. Esse resultado é complementar aos encontrados em questões anteriores (P1, P2 e P4), que tinham como temática a Mata Atlântica, arborização e desmatamento, apresentando, igualmente, resultados positivos. Logo, é possível perceber que os alunos puderam fazer uma reflexão sobre esses temas.

Neiman (2007) e Alvarenga e Nogueira-Filho (2005) também encontraram resultado similar ao desenvolverem atividades em trilhas interpretativas. Contudo, resultado diferente foi encontrado por Frederico, Neiman e Pereira (2011), que, ao realizarem atividades em uma trilha interpretativa, os autores questionaram os alunos sobre: A preservação da Mata Atlântica é urgente? No referido estudo, os autores não encontraram diferenças significativas 
entre os pré-testes e pós-testes para essa questão, significando que não houve uma mudança na manifestação de conhecimentos apresentadas por aqueles alunos. Para os autores, apesar do potencial de transformação que a experiência de contato direto com a natureza possui, a temática ambiental não foi inserida corretamente naquelas aulas de campo.

\subsection{Questões de sentimento}

A Figura 4 apresenta os resultados para as perguntas que envolvem o sentimento do aluno quanto ao tema apresentado.

Figura 4 - Valor médio e intervalo de confiança do pré-teste e pós-teste para as questões: P7 O que você sente quando ouve falar sobre a extinção de plantas e animais?; P8 - Quando estou em contato direto com a natureza eu me sinto; P9 - O que você sente quando vê árvores sendo cortadas?; e P10 - Como você fica quando vê lixo jogado no chão? (Pré-teste n=161; Pós-teste $\mathrm{n}=161$ )

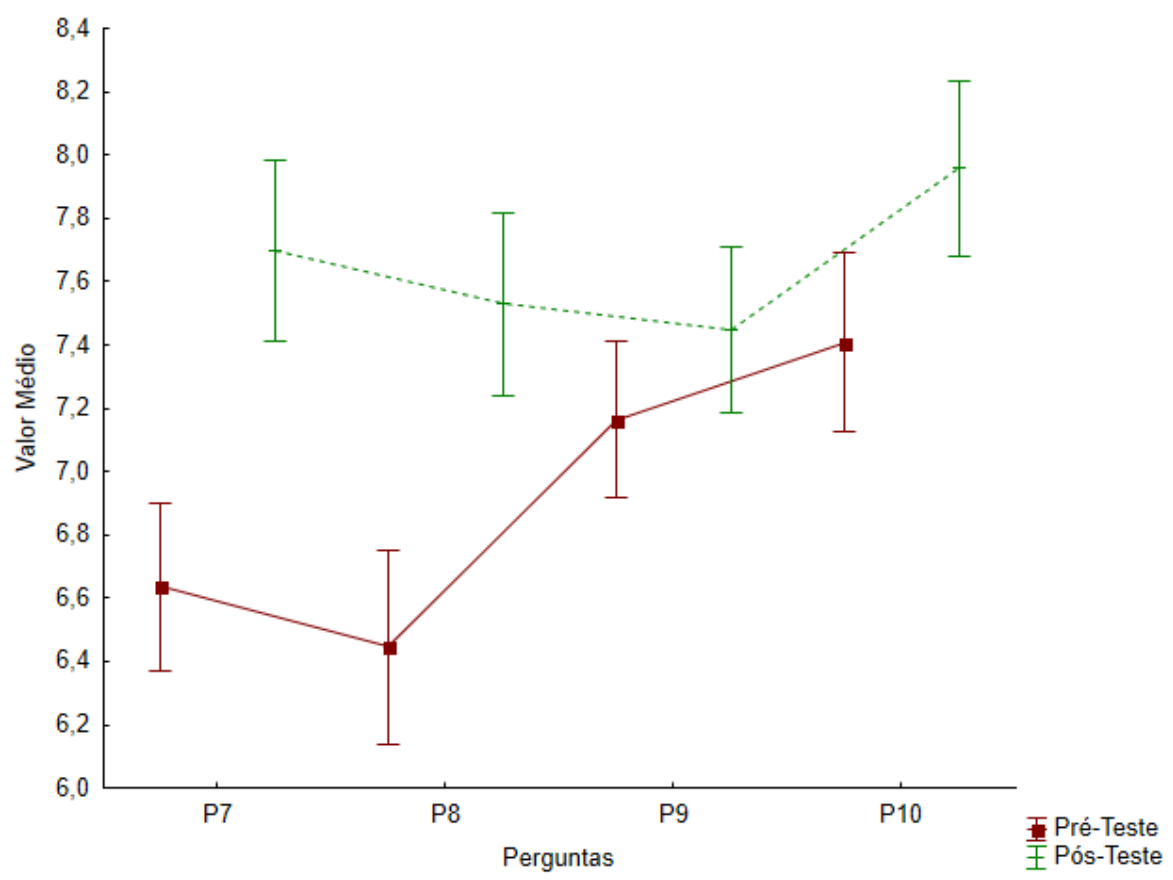

Fonte: Douglas Macali Souza (2015)

Na questão $P 7$ - $O$ que você sente quando ouve falar sobre a extinção de plantas $e$ animais?, os resultados demonstraram que houve uma mudança significativa $(p=0,000)$ na manifestação de sentimento em relação à temática. Apesar de o bairro Jardim Paraíso carecer de locais com arborização, foi possível perceber através da análise que os alunos manifestaram um sentimento que podem fazer muito ao tratar da temática de extinção de plantas e animais. Possivelmente, o histórico de criação do PMMF, apresentado aos alunos, pode ter influenciado seu sentimento. $\mathrm{O}$ antigo dono do terreno, mesmo antes de vender a área para a Prefeitura de Joinville criar o parque, já havia colocado placas, alertando para o cuidado com a vegetação, com o objetivo de manter conservado aquele local, bem como havia criado uma trilha para a comunidade contemplar a área. Possivelmente, a reflexão sobre esses 
atos influenciou os alunos a sentirem que também podem fazer alguma coisa, dar a sua contribuição.

A questão $P 8$ - Quando estou em contato direto com a Natureza eu me sinto foi a que apresentou a maior variação $(16,78 \%)$ dentre as perguntas relacionadas a sentimentos, com mudanças significativas $(\mathrm{p}=0,000)$. A manifestação dos alunos quanto ao sentimento de estar em contato com a natureza modificou-se após a realização das atividades no PMMF. Conforme mencionado anteriormente, foi possível perceber nos relatos verbais dos alunos a euforia de estarem passeando em direção à uma área natural, sentimento, este, manifestado por vários alunos. Ao final das atividades, muitos alunos manifestaram sua vontade de permanecer por mais tempo no PMMF. No trabalho realizado por Seniciato e Cavassan (2004), 84\% dos alunos responderam sentir-se confortáveis em meio a natureza, durante a aula de campo, e as justificativas apresentadas para tal sensação remeteram, principalmente, às sensações de bem-estar e prazer evidenciadas por quatro sentidos - visão, audição, olfato e tato -, pelos sentimentos de paz e tranquilidade e, também, pela descoberta e aprendizagem de coisas novas. Dentre as justificativas apresentadas para o conforto durante a aula de campo, aquelas referentes às sensações provocadas pelo ambiente foram as mais frequentes. Neiman (2007), que também contou com atividades interpretativas em trilhas, constatou uma tendência para a animação em estar próximo à mata. Resultado diferente foi encontrado por Frederico, Neiman e Pereira (2011), com graduandos de diversos cursos que, após a realização de atividades em uma trilha interpretativa, não manifestaram uma mudança de sentimentos. Possivelmente, o resultado obtido por esses pesquisadores tenha sido influenciado pela idade e nível de escolaridade dos participantes da pesquisa, pois já sabiam dos benefícios que áreas naturais podem oferecer.

Na questão $P 9$ - $O$ que você sente quando vê árvores sendo cortadas?, foi verificada uma mudança nos sentimentos manifestados pelos alunos $(\mathrm{p}=0,00)$. Estes manifestaram mais tristeza quando observam árvores sendo cortadas. Alvarenga e Nogueira-Filho (2005) também verificaram que os alunos manifestaram mais tristeza quando viam árvores sendo queimadas. Novamente, na pesquisa de Frederico, Neiman e Pereira (2011), os alunos de graduação não manifestaram mudança de sentimentos. Para os autores, esse resultado demostra que a temática ambiental não está sendo inserida corretamente nas aulas de campo, apesar do potencial de transformação que essas experiências possuem. Dessa forma, os autores concluíram que há uma grande eficiência na estratégia de contato dirigido com a natureza para a transformação dos alunos, desde que o roteiro e o trabalho educativo sejam elaborados de forma transdisciplinar, valorizando a sensibilização a partir do contato com a realidade, o que parece não ter ocorrido no estudo realizado por eles.

Para a questão P10 - Como você fica quando vê lixo jogado no chão? o valor médio das respostas no pré-teste foi de 7,41, enquanto no pós-teste a média foi de 7,96 ( $\mathrm{p}=0,000)$; ou seja, os alunos manifestaram sentir-se mais tristes quando veem lixo jogado no chão. No início da realização da trilha, um aluno aleatório foi selecionado, sem que os outros percebessem, e lhe foi entregue uma sacola. Durante o trajeto pela trilha, esse aluno, que ficou mais ao final da fila, recolheu alguns detritos encontrados no trajeto. No momento da terceira parada na trilha, quando o tema poluição foi abordado pelo guia, a sacola com os detritos foi exposta aos demais alunos. Alguns alunos ficaram impressionados por não terem percebido aqueles materiais (tampas plásticas, papéis de bala, latas) durante o trajeto. Isso pode ter acontecido pois esses materiais são comumente encontrados nas ruas em volta da escola, tornando-se objetos habituais do dia a dia dos alunos. Configurou-se, então, um momento oportuno para o guia discutir a problemática do lixo e da poluição em áreas naturais e urbanas. Do ponto de vista dos pesquisadores, essa atividade foi a grande influência para a mudança na manifestação de sentimentos dos alunos. 


\section{Conclusões}

Os resultados desta pesquisa permitem concluir que, de fato, o contato direto com a natureza é uma estratégia de sucesso para modificar a percepção ambiental dos escolares com relação ao meio ambiente, contribuindo com o processo de Educação Ambiental.

Ao analisar as respostas apresentadas antes e após a estratégia de contato com a natureza (pré-teste e pós-teste), pode-se afirmar que, baseado nos testes estatísticos, as mudanças apresentadas pelos alunos foram significativas.

As respostas apresentadas nas questões de conhecimento possibilitaram concluir que as atividades de contato direto com a natureza foram eficientes para a retenção de conhecimento por parte dos alunos. O mesmo se aplica aos sentimentos, onde os alunos apresentaram um aumento na manifestação dos sentimentos abordados, a favor da natureza. Dessa forma, os pesquisadores analisam que as atividades na trilha interpretativa serviram de ferramenta para o despertar da percepção ambiental como um todo, bem como para a conscientização dos alunos, mudando de forma positiva suas manifestações de conhecimentos e sentimentos.

Em relação à metodologia adotada para avaliar as mudanças de sentimentos e comportamentos, esta pesquisa aponta que tal método é bastante eficiente na identificação e quantificação de medidas de valores em função de os resultados mostrarem diferenças significativas. As respostas foram compatíveis com as observações de campo, ligadas ao comportamento visando à conservação do meio ambiente.

Assim, a utilização da referida metodologia mostra-se como uma alternativa para pesquisas ligadas à temática. Esta estratégia de avaliação não busca substituir os diversos métodos já pesquisados anteriormente, apenas aponta como mais uma ferramenta para pesquisas em educação ambiental.

\section{Referências}

ALVARENGA, L.C.A.; NOGUEIRA-FILHO, S.L.G. Escalas de avaliação de sentimentos: um novo instrumento para projetos de Educação Ambiental. In: III EPEA - ENCONTRO DE PESQUISA EM EDUCAÇÃO AMBIENTAL, 2005, Ribeirão Preto - SP. Anais... Ribeirão Preto. Trabalho $n^{\circ}$ 70, p. 118. Disponível em: 〈http://www.epea.tmp.br/epea2005_anais/pdfs/plenary/70.pdf >. Acesso em: 13 mai. 2015.

ALVARENGA, L. C. A. Mudando os valores na escola: Praticando Educação Ambiental. Candombá - Revista Virtual. Salvador - BA, v .1, n. 2, p.85-95, Jul./Dez. 2005.

CARVAlHO, I. C. M. Educação Ambiental: a formação do sujeito ecológico. 2 ed. São Paulo: Cortez, 2006.

CULLEN JR. L.; RUDRAN, R.; VALLADARES-PÁDUA, C. (Orgs.). Métodos de estudos em Biologia da Conservação \& Manejo da Vida Silvestre. Curitiba: Editora UFPR, 2004.

DRAY, W. T; SIMONETTI, S. R. As Trilhas Interpretativas do Parque do Mindu em Manaus - AM: utilização e conservação. In: SEMINÁRIO DE PESQUISA E TURISMO DO MERCOSUL, 7, 2012, Caxias do Sul - RS. Anais... Caixas do Sul. p.1-15. Disponível em <http://www.ucs.br/ucs/tplVSeminTur\%20/eventos/seminarios_semintur/semin_tur_7/gt06/arquivos/0 6/04_34_32_Dray_Simonetti>

FERRANDEZ, A; SARRAMONA J. La Educacion - Constantes y Problematica Actual. Barcelona: Ediciones CEAC. S.A., 1975. 
FIORI, A. Ambiente e educação: abordagens metodológicas da percepção ambiental voltadas a uma unidade de conservação. 2002. 97 f. Dissertação (Mestrado em Ecologia e Recursos Naturais) Universidade Federal de São Carlos, São Carlos, 2002.

FREDERICO, I. B; NEIMAN, Z; PEREIRA, J. C. Educação Ambiental através das visitas técnicas no ensino superior. Educação Ambiental em Ação, Novo Hamburgo-RS, n.38, ano X, dez/2011-fev/2012. Disponível em < http://www.revistaea.org/artigo.php?idartigo=1123>

FREITAS, R. E.; RIBEIRO, K. C. C. Educação e Percepção Ambiental para a conservação do meio ambiente na cidade de Manaus - Uma análise dos processos educacionais no centro municipal de educação infantil Eliakin Rufino. Revista Eletrônica Aboré, Manaus, v.3, Edição 03. Nov/2007. Disponível em <http://www.revistas.uea.edu.br/old/abore/artigos/artigos_3/Rafael\%20Estrela\%20de\%20Freitas.pdf>

FUNDAÇÃO MUNICIPAL DO MEIO AMBIENTE DE JOINVILLE - FUNDEMA - Termo de referência para elaboração do plano de manejo da Área do morro do Iririú e do Parque Municipal Morro do Finder. Joinville: Fundema, 2011.

GUIMARÃES, M. A dimensão ambiental na educação. 3. ed. Campinas: Papirus, 2000.

INSTITUTO BRASILEIRO DO MEIO AMBIENTE E DOS RECURSOS NATURAIS RENOVÁVEIS - IBAMA. Proteção e controle de ecossistemas costeiros: manguezais da Baía de Babitonga. Brasília: IBAMA, 1998. (Coleção meio ambiente. Série estudos - Pesca).

FUNDAÇÃO INSTITUTO DE PESQUISA E PLANEJAMENTO PARA O DESENVOLVIMENTO SUSTENTÁVEL DE JOINVILLE - IPPUJ. Joinville: Cidade em Dados 2014. Joinville: Prefeitura Municipal, 2014.

MAGRO, T. C.; FREIXÊDAS, V. M. Trilhas: Como Facilitar a Seleção de Pontos Interpretativos. Departamento de Ciências Florestais. Circular Técnica IPEF, Piracicaba, n. 186, p. 4-10, 1998.

MARIN, A. A.; TORRES, O. H.; COMAR, V. A Educação Ambiental num contexto de complexidade do campo teórico da percepção. Interciência, Caracas, Venezuela, v. 28. n.10. p. 616-619. 2003.

MENGHINI, F. B. As trilhas interpretativas como recurso pedagógico: caminhos traçados para a Educação Ambiental, Itajaí (SC). 2005, 103 f. Dissertação (Mestrado em Educação) - Universidade do Vale do Itajaí, Itajaí - SC, 2005.

NEIMAN, Z. A Educação Ambiental através do contato dirigido com a natureza. 2008. 234p. Tese (Doutorado em Psicologia) - Universidade de São Paulo, São Paulo, 2007.

NORRIS, H. The Action of Sedatives on Brain Stem Oculomotor Systems in Man. Neuropharmacology, Londres, v.10, n.2, p.181-191, Mar.1971.

PINHEIRO, E. S. Percepção Ambiental e a Atividade Turística no Parque Estadual do Guartelá Tibagi - PR. 2004, 146 f. Dissertação (Mestrado em Geografia) - Universidade Federal do Paraná, Curitiba, 2004.

PRIMACK, R. B.; RODRIGUES, E. Biologia da Conservação. Londrina: Ed. Planta, 2001.

RAUBER, S. C.; NETO, G. G., Percepção ambiental de um grupo de moradores de Sinop-MT: reflexões sobre o vivido e o porvir. Revista Educação, Cultura e Sociedade, Sinop, v.2, n.1, p.123138, Jan./Jun. 2012. 
ROCHA, S. A. A valorização da paisagem natural protegida em área urbana: Parque Municipal do Finder, Joinville (SC). 2006. 118 f. Dissertação (Mestrado em Geografia) - Universidade Federal de Santa Catarina, Florianópolis, 2006.

SENICIATO, T.; CAVASSAN, O. Aulas de campo em ambientes naturais e aprendizagem em Ciências - Um estudo com alunos do ensino fundamental. Ciência \& Educação, Bauru - SP, v.10, n. 01, p. 133-147. 2004.

SIEGEL, S. Estatística Não-paramétrica Para as Ciências do Comportamento. São Paulo: Ed. McGraw-Hill, 1975.

SILVA, T. S; CANDIDO, G. A.; FREIRE, E. M. X. Conceitos, percepções e estratégias para conservação de uma estação ecológica da Caatinga nordestina por populações do seu entorno. Sociedade \& Natureza, Uberlândia, v. 21, n. 2, p. 23-37. Ago. 2009.

SILVEIRA, L. R.; BRITO, E. R ; BONATTO, F. ; CHIESA, V. B. ; MARTINS, I. C. M. Utilização de Trilhas Interpretativas Como Ferramenta à Percepção Ambiental dos Estudantes de Engenharia Ambiental da UFT. Estudos, Goiânia, v. 38, n.2, p. 217-225, abr/jun. 2011.

TABANEZ, M.F., PADUA, S.M., SOUZA, M.G. A eficácia de um curso de educação ambiental não formal para professores numa área natural - Estação Ecológica dos Caetetus - SP. Revista do Instituto Florestal, São Paulo, v. 8, n. 1, p. 71-88. Jun. 1996.

TUAN, YI- FU. Topofilia: um estudo da percepção, atitudes e valores do meio ambiente. São Paulo: Difel, 1980.

VALLEJO, L. R. Unidades de Conservação: uma Discussão Teórica à Luz dos Conceitos de Território e de Políticas Públicas. Geographia, Niterói, v. 4, n. 8., p.77-106. 2002.

VASCONCELlOS, J. M. O.; OTA, S. Atividades ecológicas e planejamento de trilhas interpretativas. Maringá: Departamento de Agronomia, UEM, 2000.

Versão recebida em: 04/01/2016

Aceite em: 10/04/2016 